Portland State University

PDXScholar

\title{
Normative study of phonological process patterns of preschool children as measured by the Assessment of phonological processes, revised
}

Lori Jean Griffith

Portland State University

Follow this and additional works at: https://pdxscholar.library.pdx.edu/open_access_etds

Part of the Communication Commons, and the Phonetics and Phonology Commons Let us know how access to this document benefits you.

Recommended Citation

Griffith, Lori Jean, "Normative study of phonological process patterns of preschool children as measured by the Assessment of phonological processes, revised" (1987). Dissertations and Theses. Paper 3740. https://doi.org/10.15760/etd.5624

This Thesis is brought to you for free and open access. It has been accepted for inclusion in Dissertations and Theses by an authorized administrator of PDXScholar. Please contact us if we can make this document more accessible: pdxscholar@pdx.edu. 
AN ABSTRACT OF THE THESIS OF Lori Jean Griffith for the Master of science in Communication presented september 1 , 1987 .

Title: Normative Study of Phonological Process Patterns of Preschool Children as Measured by the Assessment of Phonological Processes-Revised

APPROVED BY MEMBERS OF THE THESIS COMMITTEE:

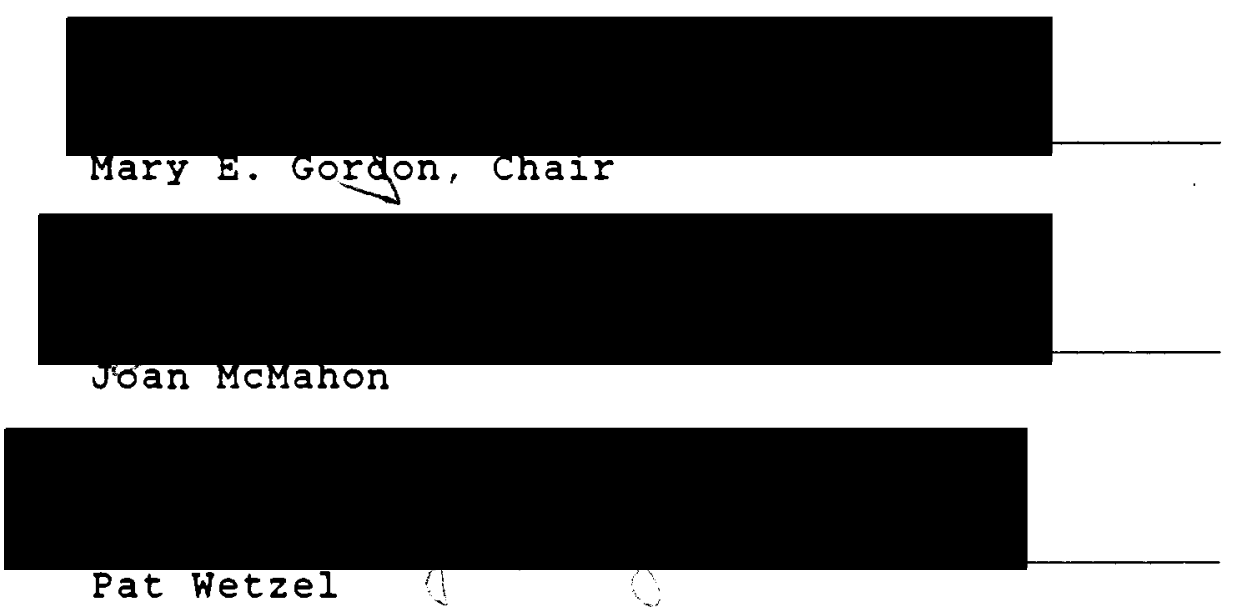

Various methods of speech diagnosis have been developed arising from a need for speech-language pathologists to analyze articulation errors. Current attention has focused on phonological process analysis. This approach analyzes how a child simplifies an adult target form of a word.

Much of the research concerning phonological processes 
has focused on disordered articulation and various methods of analysis. Little research has been conducted on normal development. As a result, most phonological process tests are without norms. The Assessment of Phonological Processes - Revised (APP-r) developed by Hodson (1986) is one test of phonological process analysis and is without norms. The purpose of this study was to obtain normative data for children ranging from 3 to 5 years of age on their use of phonological processes as measured by the APP-r. The questions this study sought to answer were: Do normally developing children exhibit phonological process deviations; what is the frequency of occurrence of each phonological process deviation by age group; and does the number of phonological process deviations and the average total frequency of occurrence of phonological process deviations decrease as age increases?

Fifty subjects, ages 2-10 to 5-2 years participated in this study. Subjects were from preschools in the portland metropolitan area.

The mean numbers of phonological process deviations exhibited by the $3,3-6,4,4-6$, and 5-year age groups were $5.7,3.6,3.0,2.0$, and 1.7 , respectively. The mean percentage of all phonological process deviations exhibited for each age group were $15.8,8.0,7.6,7.3$, and 3.6 , respectively. A one-way analysis of variance revealed a statistically significant difference at the .05 level when 
the number of ten basic process deviations exhibited was compared across age groups. In addition, a one-way analysis of variance comparing the average percentage of all phonological process deviations exhibited across age groups was statistically significant at the .05 level. As age increased, the use of phonological processes decreased.

The results of this study reveal that as age increases, the number of process deviations decrease. In addition, the average percentage of process deviations decrease as age increases. Liquid /1/, and Iiquid/r/, and strident deviations were most commonly exhibited across all age groups and prevocalic singleton omission, postvocalic singleton omission, and nasal deviation were rarely exhibited across all age groups. Although the number of subjects that participated in this study is limited. information gathered may be helpful in assessing disordered articulation with knowledge of expected performance. 
NORMATIVE STUDY OF PHONOLOGICAL PROCESS PATTERNS

$$
\text { OF PRESCHOOL CHILDREN AS MEASURED BY }
$$

THE ASSESSMENT OF PHONOLOGICAL PROCESSES-REVISED

by

LORI JEAN GRIFFITH

A thesis submitted in partial fulfillment of the requirements for the degree of

\author{
MASTER OF SCIENCE \\ in \\ SPEECH COMMUNICATION \\ with emphasis in \\ SPEECH-LANGUAGE PATHOLOGY \\ Portland State University
}


TO THE OFFICE OF GRADUATE STUDIES AND RESEARCH:

The members of the Committee approve the thesis of Lori Jean Griffith presented September 1, 1987.
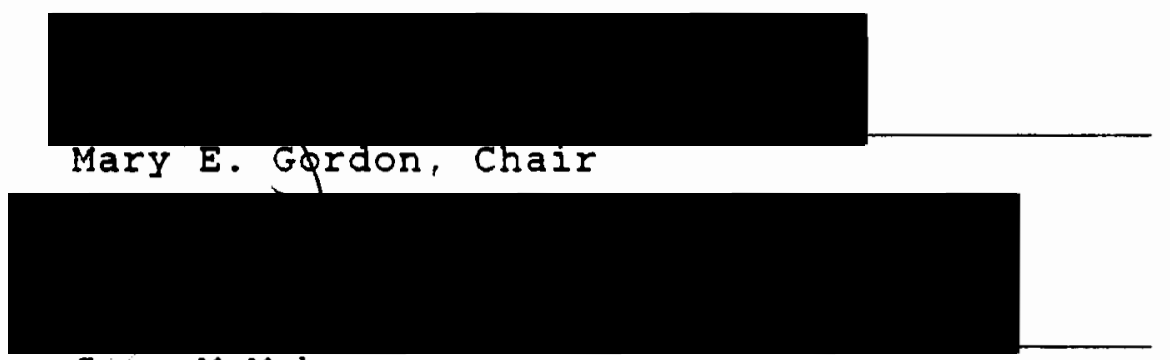

Joan McMahon

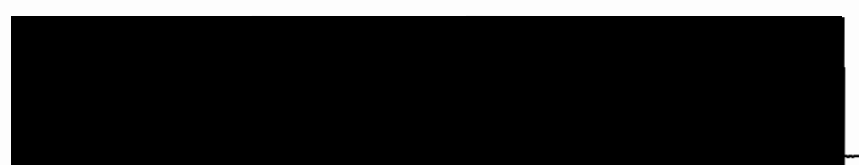

Pat Wetzel

\section{AP PROVED :}

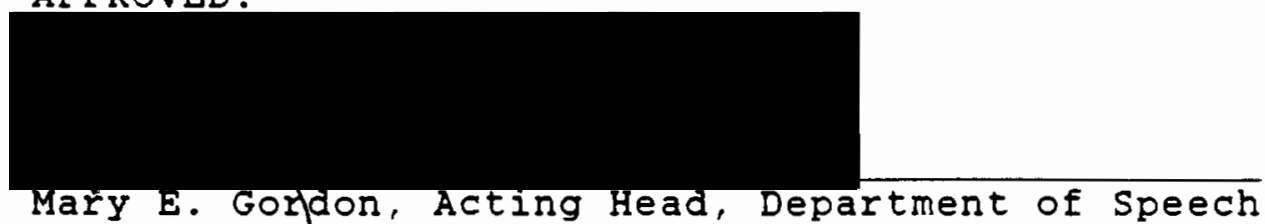

Communication

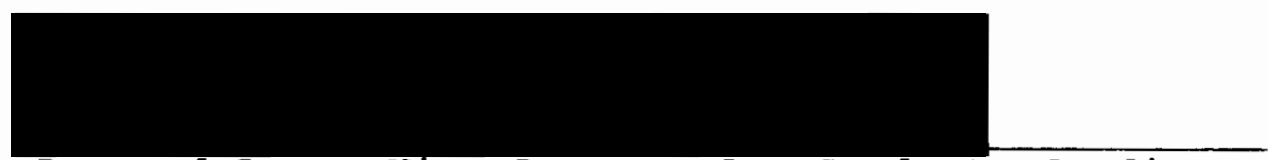

Bernard Ross, Vice Provost for Graduate studies 


\section{ACRNOWLEDGEMENTS}

I would like to acknowledge Mary E. Gordon for her guidance and patience. Without her help and flexibility the completion of this project would not have been possible. I appreciate her fondness of cats.

I would also like to thank Joan McMahon for her assistance with this project. In addition, I greatly appreciate the guidance, advice, and constant support that she has given to me throughout graduate school.

Most of all, I wish to thank my parents, Jerry Griffith and Ruth Hoffart Griffith, whose love, patience, and support have always been there. I thank my father for his long spent hours working at the computer with me. I dedicate this thesis to them. 
TABLE OF CONTENTS

PAGE

ACKNOWLEDGMENTS . • . . . . . . . . . . . . . . . iii

LIST OF TABLES . . . . . . . . . . . . . . . . . vi vi

LIST OF FIGURES . . . . . . . . . . . . . . . . . vii v vi

CHAPTER

I INTRODUCTION AND STATEMENT OF PURPOSE . . . 1

II REVIEW OF THE LITERATURE . . . . . . . . . . 6

Approaches to the Assessment of

Articulation . . . . . . . . . 6

Phonological Processes . . . . . . . 8

Phonological Process Development . . . . 12

Phonological Process Analysis . . . . 21

III METHODS AND PROCEDURES . . . . . . . . . 26

subjects ............ . . . 26

Instrumentation . . . . . . . . . 27

Procedures . . . . . . . . . . 27

Test Administration....... . 27

Reliability . . . . . . . . . 28

Data Measurement and Analysis . . . . 29

IV RESULTS AND DISCUSSION . . . . . . . . . 31

Results . . . . . . . . . . . . 31 
Discussion . . . . . . . . . . . . . . 41

$\mathrm{V}$ SUMMARY AND IMPLICATIONS . . . . . . . . . . . 46

summary . . . . . . . . . . . . . . 46

Implications . . . . . . . . . . . . 48

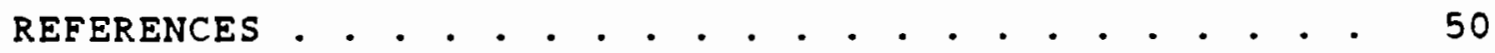

APPENDIX . . . . . . . . . . . . . . . . . . . . . 53 


\section{LIST OF TABLES}

TABLE

PAGE

I Chomsky-Halle Distinctive Feature Chart . . . . 8

II Comparison of Types of Phonological Processes

Described by Various Authors . . . . . . 10

II Phonological Processes Disappearing by $3-0$ and

Persisting Beyond 3-0. . . . . . . . . . 21

IV Mean, Standard Deviation, and Range of the

Number of Phonological Process Deviations

Exhibited by All Children . . . . . . . . 34

$\checkmark$ Mean Percentage of the Frequency of Occurrence

of Each Process Deviation by Age Group . . . 36

VI Mean, Standard Deviation, and Range of the

Average Percentage of Possible

Phonological Process Deviations Produced

by All Children . . . . . . . . . . . 38

VII Mean, Standard Deviation, and Range of the

Number of Phonological Process Deviations

Exhibited by Each Age Group . . . . . . . 39

VIII ANOVA Summary Table Comparing the Number of

Phonological Processes Produced for Age

Groups . . . . . . . . . . . . . . . . 40 
IX Mean, standard Deviation, and Range of the Average Percentage of Possible Phonological Process Deviations for Each Age Group . . . 40 $X$ ANOVA Summary Table Comparing the Average Percentage of Possible Phonological Process Deviations for Age Groups . . . . . . . . 41

XI Ten Basic Phonological Processes in Order of Frequency of Occurrence for All subjects . 45 


\section{LIST OF FIGURES}

FIGURE

PAGE

1. Chronology of Phonological Processes... . 20

2. Number of Subjects Exhibiting Each Phonological Process Deviation . . . . . . . . 33

3. Number of Subjects Exhibiting Each Phonological Process Deviation . . . . . . . . . 33

4. Number of Subjects Exhibiting Each Phonological Process Deviation . . . . . . . . . 33

5. Average Percentage of Occurrence of Each

Phonological Process Deviation... . . 37

6. Average Percentage of Occurrence of Each

Phonological Process Deviation. . . . . 37

7. Average Percentage of Occurrence of Each

Phonological Process Deviation... . . 37 


\section{CHAPTER I}

\section{INTRODUCTION AND STATEMENT OF PURPOSE}

\section{INTRODUCTION}

Methods of speech diagnosis have developed from a need for speech-language pathologists to analyze speech errors. Various approaches include phonemic analysis; analysis of speech according to place, voice, and manner; distinctive feature analysis; and phonological process analysis. Historically most speech-language pathologists have conceived of disordered speech as the result of phonemic differences which involve describing error sounds in terms of omissions, substitutions, additions, and distortions. During the 1980's, phonological process analysis was developed to meet the need of assessing a child's phonological patterns. The phonological approach involves assessing a child's speech patterns or rules and differs from a phonemic approach in that the linguistic rules underlying speech production are analyzed as contrasted to single phonemic analysis.

Current attention has focused on phonological process analysis. The term phonological process deviation refers to "a regularly occurring deviation from standard adult speech patterns" (Elbert and Geirut, 1986). The analysis describes 
the way a child simplifies an adult target form. An example of a process is "gliding" which is marked when glides (/w) and $/ j /)$ are substituted for other phonemes (e.g., "rock" produced as /wak//.

Research concerning phonological process analysis has focused mainly on the deviations of child speech. Few studies have been conducted on normal development and suppression of phonological process deviations and as a result, most phonological process analyses are without age norms. Attention to developmental norms could serve as a foundation in the comparison of normal and articulation delayed children (Haelsig and Madison, 1986). Information regarding normal development could further an understanding of child phonology by adding to the already existing knowledge concerning appearance, productive duration, and disappearance of phonological process deviations in the critical preschool period (Haelsig and Madison, 1986).

The Assessment of Phonological Processes-Revised developed by Hodson (1986) is a widely used test and is easy to administer. However, this test is without developmental norms. Evaluating a child who is phonologically delayed requires an understanding of normal process development. Normative data could serve as a reference for assessing phonological performance. 


\section{STATEMENT OF PURPOSE}

The purpose of this study was to obtain normative data on preschool children aged three years to five years on their use of phonological process deviations as measured by the Assessment of Phonological Processes-Revised (APP-r) developed by Hodson (1986). This investigation sought to answer the following questions:

1. Do normally developing children exhibit phonological process deviations?

2. What is the frequency of occurrence of each phonological process deviation by age groups?

3. Does the number of phonological process deviations decrease as age increases?

4. Does the average total frequency of occurrence of phonological process deviations decrease as age increases?

\section{DEFINITION OF TERMS}

The following terms are ten basic phonological process deviations which are analyzed by the Computer Analysis of Phonological Processes (CAPP) developed by Hodson (1985). For additional phonological process terms refer to Appendix A (Weiss, Gordon, and Lillywhite, 1987).

Consonant Sequence Reduction: occurs when any consonant in a sequence (not separated by a vowel) is omitted (e.g., (trig' for "string"). 
Velar Deficiency: occurs whenever velar stops $/ \mathrm{k} /$ and $/ \mathrm{g} /$ are omitted or when some phoneme other than $/ \mathrm{k} /$ or $/ \mathrm{g} /$ is substituted (e.g., /^m/ or /dnm/for "gum").

Glide Deficiency: is scored when substitutions for /w/ or /j/ from other classes occur or when they are omitted le.g., /at J/ or batf/ for "watch").

Liquid (1): is scored when /1/ is omitted or when some other phoneme is substituted (e.g., /if/ or /wif/ for "leaf").

Liquid $(r)$ : is scored when $/ r, \sigma /$ is omitted or when some phoneme other than $/ \mathrm{r} /$ is substituted (e.g., /ak/ or /wak/ for "rock").

Nasal Deficiency: is scored when $/ \mathrm{m} /, / \mathrm{n} /$, or $/ \eta /$ target phonemes are omitted or when nonnasal phonemes are substituted (e.g., /ouz/ or /douz/ for "nose").

Prevocalic Singleton Consonant Omission: is scored whenever a singleton consonant that initiates a syllable is deleted (e.g., /ou ou/ for "yoyo").

Postvocalic singleton Consonant omission: is scored whenever a singleton consonant omission that terminates a syllable is deleted (e.g., /wa/ for "watch").

Stridency Deletion: is scored whenever stridency is deleted either by means of a total omission of the target strident phoneme (e.g., /u/ for "shoe") or by substitution of a nonstrident phoneme (e.g., /tu/ or /wu/for "shoe"). 
Syllable Reduction: is scored when an entire syllable nucleus is deleted in a stimulus word that has two or more syllables (e.g., /bæ/ for "basket"). 
CHAPTER II

REVIEW OF THE LITERATURE

The assessment of speech errors has many approaches with the most recent approach being phonological process analysis. This chapter presents a historical framework concerning analysis methods dating from Van Riper in the $1950^{\prime} \mathrm{s}$ and continuing to the more current methods of phonological processes. Phonological development will also be discussed and particular emphasis will focus on Hodson's (1986) method of phonological process analysis to provide background information on why normative data are necessary.

\section{APPROACHES TO THE ASSESSMENT OF ARTICULATION}

One of the earliest approaches to articulation analysis was developed by Van Riper in the 1950's. This type of analysis is often labeled as "traditional" (Elbert and Geirut, 1986). Each speech sound is assessed according to its position in the word, i.e., initial, medial, and final. This phonemic analysis describes error sounds in terms of omissions, substitutions, and distortions. Each sound is considered separately from the others. Traditional analysis is still used today and may be appropriate for a 
child who consistently misarticulates specific sounds or who has a phonetic, i.e., motoric articulation disorder.

A later type of analysis focuses on the relationship of error sounds with the phonemic systems of the place, voicing, and manner characteristics of production. Every sound is analyzed according to these three features and thus is distinguished from every other sound. for example, the feature combination of lingual-alveolar voiceless stop describes only the /t/ sound (Elbert and Geirut, 1986). An example of this type of analysis includes the compton-Hutton Phonological Assessment (Compton and Hutton, 1978).

Finally, a type of analysis which gave rise to the current phonological process analysis is distinctive feature analysis. In contrast to other analyses, the distinctive feature approach gathers an extensive speech sample of multiple productions of each sound and studies which features are used correctly and which are used incorrectly (Elbert and Geirut, 1986). Each phoneme is analyzed as a "bundle" of distinctive features and is distinguished from all other phonemes by its unique combination of features (Stoel-Gammon and Dunn, 1985). The distinctive features approach groups phonemes into classes on the basis of shared features. For example, $/ \mathrm{m} /, / \mathrm{n} /$, and $/ \mathrm{g} /$ share the nasal feature and thus form a class of nasal consonants (stoelGammon and Dunn, 1985). Examples of these phonemic systems 
are included in the Chomsky-Halle Distinctive Feature Chart (Chomsky and Halle, 1968) presented in Table I.

\section{Table I}

Chomsky-Halle Distinctive Feature Chart

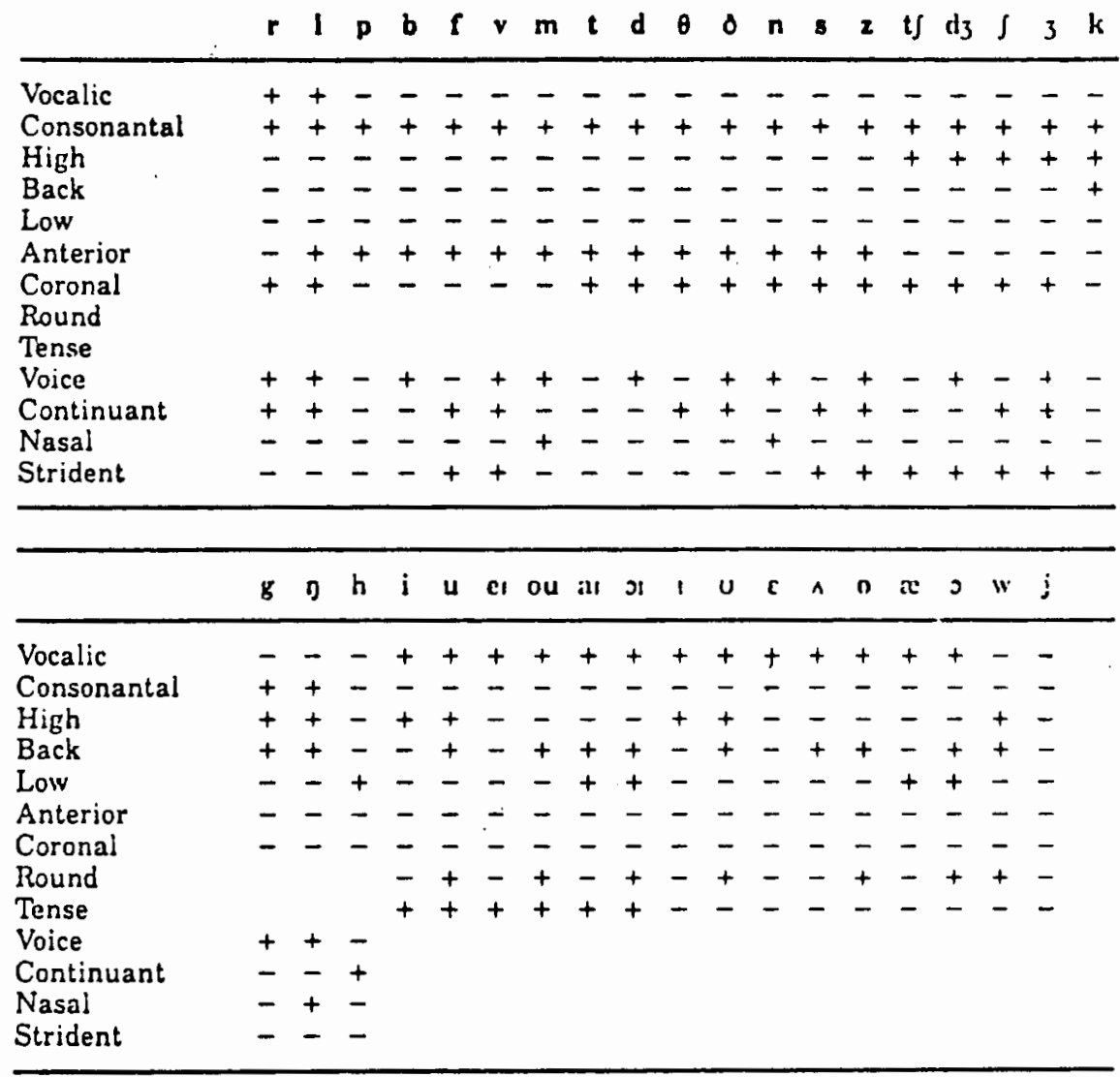

Note: $+/-$ represent the presence or absence of the features of each phoneme.

(From: Chomsky, N., and Halle, M. (1968). The sound pattern in English. New York, NY: Harper and Row.)

\section{PHONOLOGICAL PROCESSES}

The most recent approach to the assessment of articulation is phonological process analysis. A phonological process deviation is a sound pattern that has 
been observed in the speech of an individual. The underlying form of a word is generally considered to be the adult form of the word (Kahn, 1985).

Sound patterns or process deviations have been classified differently according to various authors. Hodson (1986) separates phonological process deviations according to omissions, major phonemic substitutes, assimilations which include sound deviations assuming a characteristic of another sound in a word (e.g., /kwnk/ for "truck"), miscellaneous deficient patterns, idiosyncratic rules which include deficient patterns that do not fit into any of the classifications Hodson describes, epenthesis which includes adding a vowel or consonant in a word le.g.,/balak/for "black"), voicing alterations, vowel deviations, and nonphonemic alterations which may include tongue positioning and other structures of the speech mechanism apart from a target phoneme.

Another classification system was developed by Weiner (1979) and includes (a) syllable structure processes which involve changes in the make-up of the syllable of the adult form of the word, (b) harmony processes which include sound deviations that are influenced by other sounds in a word, and (c) features contrast processes which include sound substitutions without the influence of other phonemes. Harmony processes as described by Weiner are analogous to assimilation processes as described by Hodson (1986). 
A classification system somewhat similar to Weiner's (1979) is Ingram's (1981) system which includes syllable structure processes, substitution processes, simplification of liquids and nasals, other substitution processes, and assimilation (or harmony) processes. Similarly, Elbert and Geirut (1986) describe three basic types of process deviations: processes that delete segments, processes that substitute segments, and processes that assimilate segments. Table II is a comparison chart developed by Kahn (1985) to describe phonological process deviations used by various phonologists.

\section{TABLE II}

Comparison of Types of Processes Described by Various Authors

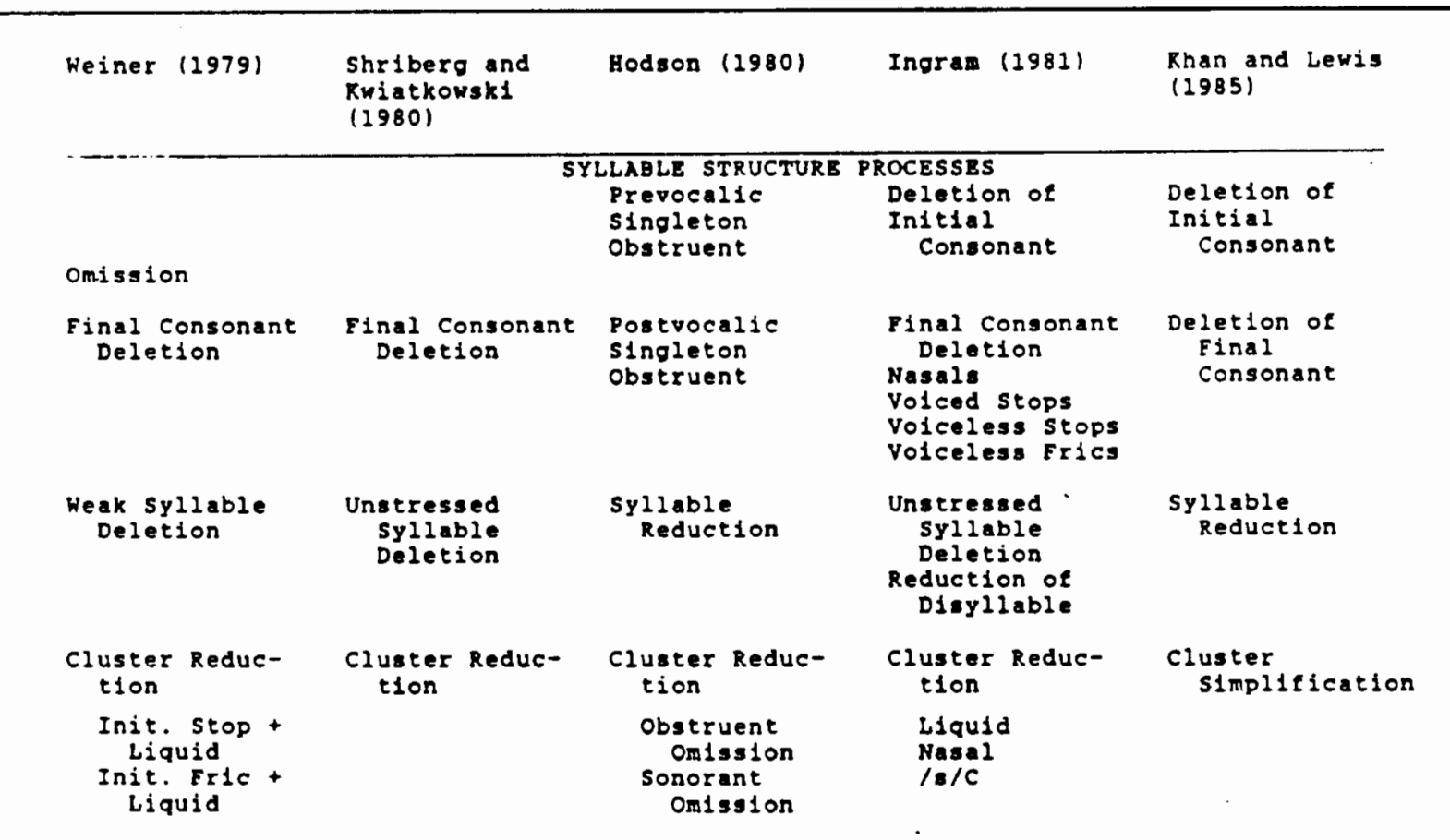




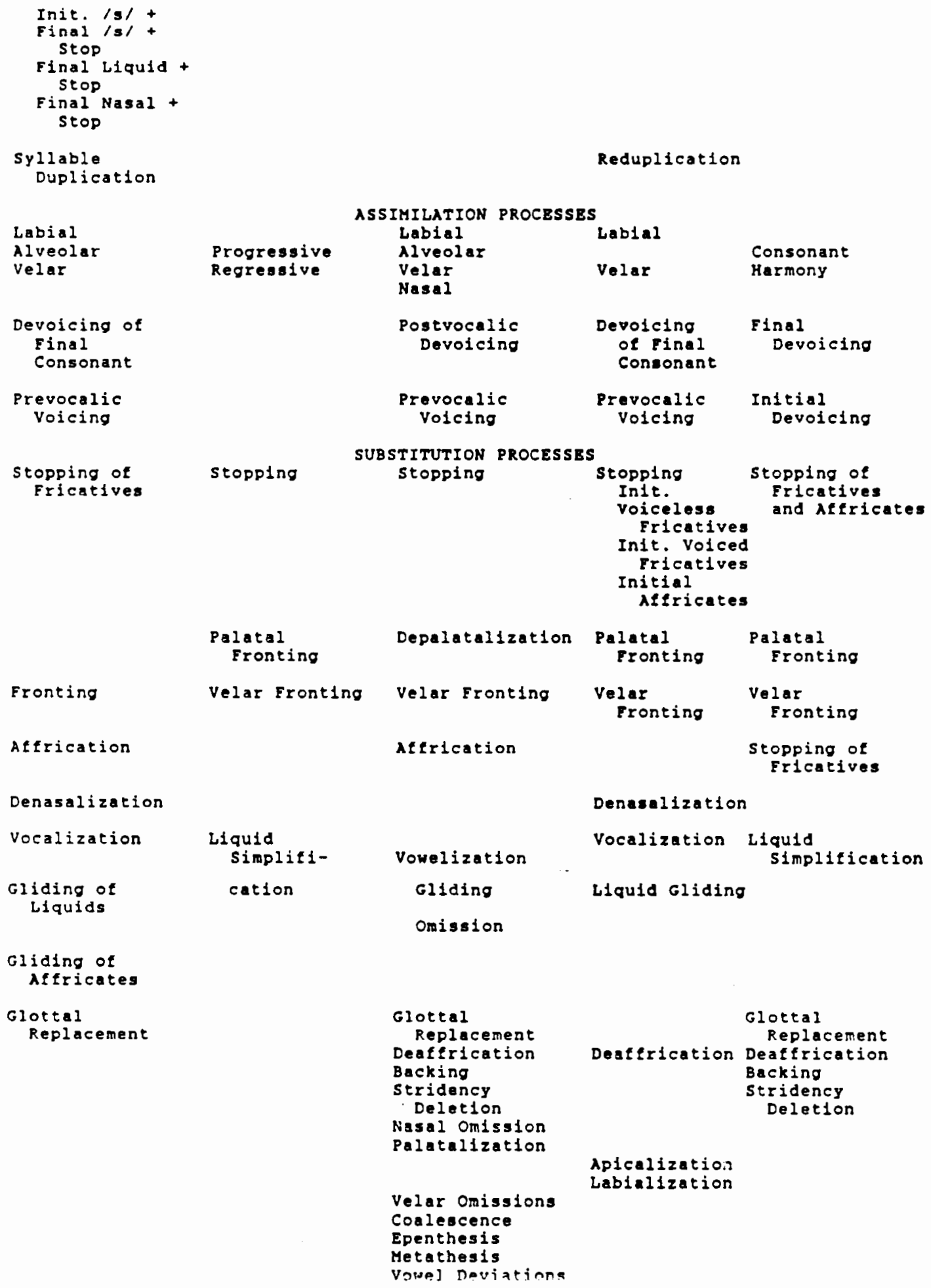

(From Kahn, L.M.: Basis of Phonological Analysis: A Programmed Learning Text, San Diego, CA, College-Hill Press). 
It can be seen that the authors describe similar process deviations, but use a number of various terms to describe them.

\section{PHONOLOGICAL PROCESS DEVELOPMENT}

A number of studies have been conducted concerning normal phonological development. These studies have contributed to phonological process theory.

Smith (1973) studied his son Amahl from age 2-0 to 4-0 and postulated a set of ordered "realization rules" written in distinctive feature notation. These "realization rules" mapped the adult forms onto the child's surface forms. The surface form is the term used to identify the child's actual response.

A study by Edwards (1973) involved the acquisition of liquids. She postulated several "natural" phonetically possible phonological processes that could account for all the liquid substitutions and omissions in the speech of her six subjects. For example, surface substitutions of $/ \mathrm{w} /$ for $/ Y /$ were broken down into their constituent processes or components of each process (e.g., labialization process which causes a consonant to be rounded due to the influence of a preceding phoneme). In addition, Edwards also showed how the processes that she postulated were gradually limited and suppressed by the children in her study as their ages increased. Research with her subject Daniel lends an 
example of this developmental sequence. Daniel at the age of 1-6 to 1-7 exhibited liquid loss relating to preconsonantal liquids (e.g., /mak/ for "milk") and liquids after noncoronal consonants, (e.g., /kaka/ for "glasses"). Later, Daniel limited liquid loss as it related only to round liquids following a high back vowel, (e.g., /wuf/ for "wolf"), but liquids in other phonemic contexts were produced.

Oller (1973) obtained speech samples of five children with delayed articulation. He formalized "substitution rules" to describe the sound errors. He noted that all five of his subjects exhibited cluster reduction process deviations and some fricative and/or affricative substitution process deviations. For example, /f, $\delta, \theta, /$ were replaced by $/ \mathrm{h} /$ in nonfinal positions. His results revealed that children whose speech was highly unintelligible had phonological systems which were as structured and regular as those children whose speech was developing at a normal rate. The children's speech resembled those of normal children at earlier ages.

Ingram (1974) agreed with oller (1973), and stated that a number of "general" phonological rules are found in normal phonological development. He explained phonological rules and how they were related between the child and adult forms and noted that the use of phonological rules demonstrated the organizational and generalizing capacities of the child. 
Ingram (1981) researched the phonological process deviations used by fifteen normal and fifteen languagedelayed children with mean chronological ages of $1-9$ and 54, respectively. Results revealed that many of the same process deviations were observed in both groups. Ingram also noted that some processes were unique for each group. This implies a need for more data reflecting normal development.

Leonard, Miller, and Brown (1980) researched the use of two process deviations, consonant assimilation and reduplication, in the speech of eight children with language delays with ages ranging from 3-8 to 4-10. Assimilation occurs when one consonant is influenced by another (e.g., /kok/ for "coat") and reduplication occurs when two syllables are produced identically or more similarly (e.g., /baba/ for "bottle"). It is postulated by various authors that normal children exhibit these process deviations in order to compensate for the inability to produce a more complex word and Leonard et al. (1980) sought to determine if children with language disorders did the same. The results revealed that assimilation allowed language disordered children to use words containing difficult target consonants without actually producing those consonants. Additionally, the language disordered children exhibited reduplication in attempting to produce nonreduplicated multisyllabic words, thus allowing them to produce 
multisyllabic words. Thus, these results also indicated that reduplication may compensate for the inability to produce a difficult target phoneme and yet produce multisyllabic words.

Schwartz, Leonard, Folger, and Wilcox (1980) studied phonological development in three language-disordered ages ranging from $2-7$ to $3-7$ and three normal children, ages ranging from 1-7 to $1-9$, respectively. In relation to phonological process deviations, they found that there were more similarities than differences between the two groups. The most frequently occurring process deviation for all of the language-disordered children and two of the normal children was final consonant deletion. They did find a difference between the two groups in the frequency of occurrence of particular process deviations. Reduplication was more frequently exhibited among the normally developing children than among the language disordered children. In addition, the researchers found that language disordered children did not exhibit a larger number of phonological process deviations than the normally developing children. They suggested that differences between the two groups may have indicated individual variation more than group differences.

Hodson and Paden (1981) researched the phonological process deviations of sixty intelligible and sixty unintelligible 4-year-olds. The main focus was to determine 
which of the process deviations were operating in the unintelligible children. They also sought to determine what process deviations were being exhibited by the intelligible children and then compare the two groups. They discovered that the groups differed in their production of specific phonological process deviations. All sixty unintelligible children used stopping, cluster reduction, stridency deletion, liquid deviations, and assimilation in their speech. Other process deviations exhibited by the unintelligible children included velar deviations, final consonant deletion, syllable reduction, prevocalic voicing, and others. In contrast, the normal 4-year-olds produced very few process deviations. Process deviations included devoicing, liquid deviations, vowelization, gliding, and assimilations. The only process deviation which all intelligible children exhibited was devoicing. Hodson and Paden also noted that most of the process deviations exhibited by the unintelligible children did not occur in the speech of the intelligible children. They concluded that the process deviations produced by the sixty unintelligible children varied in the number and type of process deviations from those produced by the sixty intelligible children.

Preisser (1983) studied use of phonological process deviations for twenty children in three age groups ranging in age from $1-6$ to $2-5$. She administered the Assessment of 
Phonological Processes-Revised and found that as age increased, the percentage of occurrence of phonological process deviations decreased. For example, children ranging from 1-6 to 1-9 exhibited cluster reduction 93 percent of the time and children ranging from 2-2 to 2-5 only produced cluster reduction 51 percent of the time.

Haelsig and Madison (1986) have recently studied the normal development of phonological processes in fifty children with ages ranging from 2-10 to 5-2 years. Their study involved administering the Phonological Process Analysis (PPA) developed by Weiner (1979) and making comparisons among age groups. They found that a decrease in the number of process deviations occurred as age increased. Fifteen out of the sixteen possible process deviations were exhibited by the 3-year-old age group whereas nine of the sixteen possible process deviations were produced by the 5year-old group. Gliding of liquids was the most frequently occurring process deviation in the $3-0$ and $3-6$ year-old groups, whereas gliding did not occur in the 5-year-old group. No significant difference was found relative to the gender of the child. Many process deviations were rarely exhibited by the children, including prevocalic voicing, affrication, and denasalization. In addition, many children did not exhibit all of the phonological process deviations. Hodson and Paden (1983), Kahn and Lewis (1985), and Weiner (1979) list phonological process deviations according 
to a developmental sequence. Hodson lists the process deviations by severity levels; (a) $\underline{0}$ which includes omissions, (b) 1 which includes omissions, major place substitutes, glottal replacement, voicing alterations, miscellaneous patterns, vowel deviations, and idiosyncratic rules; (c) $\underline{2}$ which includes omissions, i.e., cluster reduction, and major phonemic substitutes, and (d) $\underline{3}$ which includes nonphonemic alterations, major phonemic substitutes, and voicing alterations. Kahn and Lewis list the process deviations according to (a) first, which includes deletion of final consonants, initial voicing, syllable reduction, palatal fronting, and deaffication; intermediate, which includes velar fronting, consonant harmony, and stridency deletion; and (c) last, which includes stopping of fricatives/affricatives, cluster simplification, final devoicing, and liquid simplification. Weiner lists phonological process deviations in three major categories; (a) syllable structure processes, which include deletion of final consonant, cluster reduction, weak syllable deletion, and glottal replacement; (b) harmony processes, which include labial assimilation, alveolar assimilation, velar assimilation, prevocalic voicing, and final consonant devoicing; and (c) feature contrast processes, which include stopping, gliding of fricatives, affrication, fronting, denasalization, gliding of liquids, and vocalization. Although some variability exists, the 
developmental sequences of phonological process deviations listed by each author are in basic agreement. For example, Hodson, Rahn-Lewis, and weiner agree that deletion of final consonants (prevocalic singleton omission), syllable reduction, and prevocalic voicing (initial voicing) are all produced early in phonological development. These developmental sequences also have implications for the course of articulation treatment.

Grunwell (1983) has identified various phonological process deviations and listed their approximate sequence in development (Figure 1). Shriberg and Kwiatkowski (1980) stated that between the ages of 1 and 4 years all phonological processes disappear except for a few residual occurrences. Table III represents process deviations that disappear by the age of 3 and process deviations that persist beyond age 3 as reported by Stoel-Gammon and Dunn (1985). 


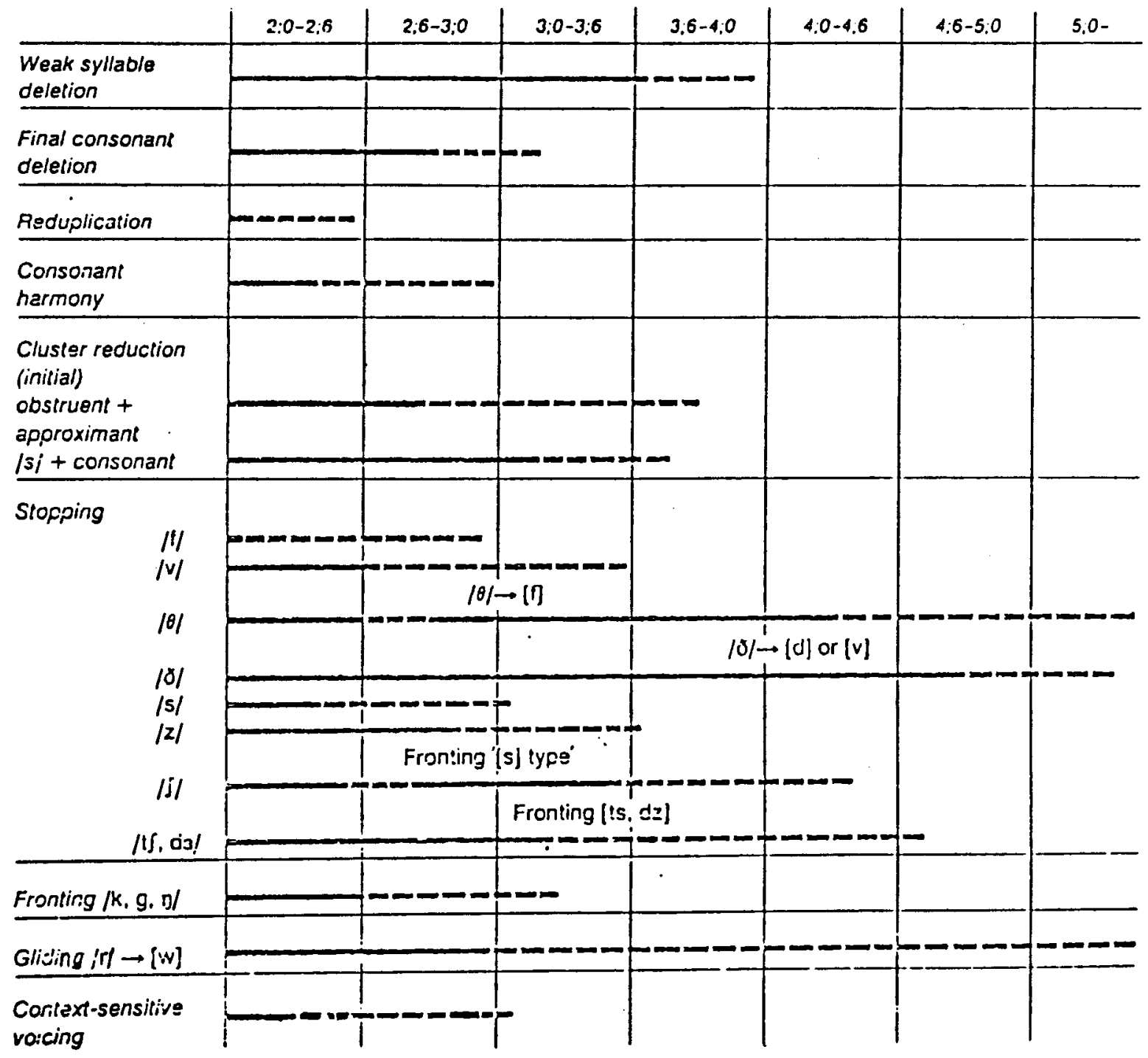

Figure 1. Chronology of phonological processes (From Grunwell, P.: Clinical Phonology, Rockville, MD, Aspen Systems Corporation, 1983, p. 183). 
TABLE III

Processes Disappearing by 3-0

and Persisting Beyond 3-0

Disappearing

Unstressed syllable deletion

Final consonant deletion

Doubling

Diminutization

Velar fronting

Consonant assimilation

Reduplication

Prevocalic voicing
Persisting

Cluster reduction

Epenthesis

Gliding

Vocalization

Stopping

Depalatization

\section{PHONOLOGICAL PROCESS ANALYSIS}

In the early 1970's Ingram (1974) was interested in what was occurring when a child begins acquiring articulatory patterns. He suggested that it is necessary to look at the rule system of the child's phonological

development, and his research contributed to the development of phonological process analysis.

As stated previously, a phonological process deviation is a regularly occurring deviation from a standard adult speech pattern. It is a descriptive rule or statement which accounts for errors of substitution, omission, and addition (Elbert and Geirut, 1986). In this type of analysis the child is viewed as attempting to produce all segments of the adult target, but for reasons related to immature motor, 
cognitive, perceptual, or linguistic capabilities, the child simplifies the adult target (Elbert and Geirut, 1986).

A number of tests have been developed to describe these rule-governed process deviations. While each test differs in several respects, most of them are based on Stampe's (1969a) theory of natural phonology. According to Stampe (1969b) who first described these natural patterns or processes, there are certain innate tendencies to simplify speech production. Stampe (1969c) stated that the child's pronunciation is derived from his or her "mental representation" of adult speech. For example, Stampe (1972) stated that the process of depalatization "eliminates the fronted and raised tongue posture of $/ \mathrm{S} / \mathrm{J} /$ in favor of a more neutral posture of alveolars /s,z/."

The PPA is an analysis procedure, without norms, for assessing the speech of unintelligible children ranging from 2 to 5 years. Approximately twenty process deviations are elicited using action pictures. Responses are elicited in single words and phrases. Each child's utterance is then transcribed and scored in the + or - column for the presence or absence of a phonological process deviation.

Another test, Shriberg and Kwiatkowski's (1980) NPA is different from most of the phonological process analyses. Instead of naming responses, a spontaneous speech sample is obtained from the child and only eight "natural" process deviations, i.e., final consonant deletion, velar fronting. 
stopping, palatal fronting, liquid simplification, assimilation, cluster reduction, and syllable deletion, are analyzed. Scoring involves "coding" (identifying the processes) the words that are transcribed. Three coding sheets exist. Sheet A includes words containing nasals, glides, and liquids; sheet $B$ is for oral stop consonants; and sheet $C$, for fricatives and affricates. This test is also without norms.

\section{Ingram's (1981) Procedures for the Phonological}

Analysis of Children's Language consists of four procedures including phonetic analysis, analysis of homonymy. substitution analysis, and phonological process analysis. Phonological process analysis only will be discussed here. This procedure involves obtaining a speech sample and then calculating the percentage of occurrence of twenty-seven phonological process deviations (Table II). Ingram's analysis is without norms.

The RLPA is a phonological analysis in which the Goldman-Fristoe Test of Articulation (Goldman and Fristoe, 1969 ) is utilized. Responses are then transcribed on a score sheet for the RLPA which identifies twelve developmental and three nondevelopmental phonological process deviations. The RLPA does have developmental norms ranging from 2-0 to 5-11.

The APP-r is an analysis which obtains fifty elicited responses from a child naming three-dimensional objects. 
The responses are transcribed and scored according to the percentage of occurrence of ten basic phonological process deviations and this test does not have norms. The Computer Analysis of Phonological Processes (CAPP) also developed by Hodson (1985) can be used to analyze the fifty responses. A one-page printout gives the percentage of occurrence for ten phonological process deviations, a phonological deviancy score, and one or more goal statements. 


\section{SUMMARY}

A number of approaches exist in analyzing the speech of children. The most current analysis method is phonological process analysis.

Studies have been conducted using phonological process analyses of delayed articulation among children. Few studies have been conducted regarding normal development of phonological process usage. Those studies that have been conducted suggest more research needs to be done in order to determine at what ages phonological process deviations occur. some research in this area is in progress. Since most phonological process tests are without norms, further research in this area is warranted. The APP-r by Hodson is one such test and will be the focus of this study. 
CHAPTER III

METHODS AND PROCEDURES

METHODS

\section{subjects}

Subjects were selected from preschools in the Portland, Oregon, metropolitan area. Fifty children aged 3 years to 5 years participated as subjects in the study. of these subjects, ten children were chosen for each of five age groups: $3,3-6,4,4-6$, and 5 .

The subjects met the following criteria:

1. The parent or guardian signed a release form giving permission to participate in the study (Appendix B).

2. The child was within \pm 2 months of his/her designated chronological age group at the time of testing.

3. The child had no history of speech and/or language problems as reported by the parent.

4. The child had no history of chronic middle-ear infections as reported by the parent.

5. The child had no mental or neurological handicaps as reported by the parent and/or teacher.

6. The child passed a unilateral, pure tone audiometric screening test administered at $25 \mathrm{~dB} \mathrm{HL}$ for the frequencies of $500,1000,2000$, and $4000 \mathrm{~Hz}$. 


\section{Instrumentation}

The Assessment of Phonological Processes - Revised $(A P P-r)$ by Hodson (1986) in conjunction with the Computer Analysis of Phonological Processes (CAPP) developed by Hodson (1985) is an instrument to evaluate a child's phonological skills. The test consists of fifty target words which are elicited as the child chooses and names three-dimensional objects. Hodson (1986) suggests that the examiner tape record the utterances for increased accuracy in transcribing. The utterances are transcribed and then examined to identify deviations between the child's productions and the adult target forms. These deviations are described according to the type of patterns or phonological process deviations that are exhibited. Phonological process deviations analyzed by the CAPP include syllable reduction, prevocalic singleton omission, postvocalic singleton omission, consonant sequence reduction, strident deviation, velar deviation, liquid and liquid ( $r$ ) deviations, nasal deviation, and glide deviation (Appendix D).

\section{PROCEDURES}

\section{Test Administration}

The screening and testing was performed at the preschools of the individual subjects. Each potential subject was brought into a quiet, well-lit room. The 
investigator engaged the subject in conversation to establish rapport. Following conversation, audiometric screening was completed prior to administration of the APP$r$. If the subject met selection criteria, the APP-r was administered.

During the testing situation, the subject and investigator were seated on the floor facing each other. The investigator emptied a box of fifty three-dimensional objects which represented the fifty target words. The investigator instructed the child to choose an object, name it, and put it in the box. She used verbal (social) reinforcement as necessary to keep the child on task. If the child said the wrong word, said "I don't know," or did not name an item spontaneously, the investigator said the stimulus word and then instructed the child to say the name of the stimulus word. Ideally, conversation was included before the child named the object. The investigator repeated the words after the child in the event of any unintelligible words. All responses were tape recorded. Misproductions were noted on the APP-r response form during the test situation (Appendix C).

Reliability

A random selection of five audiotapes, one from each age group, were transcribed and scored using the CAPP by two speech-language pathology graduate students. A Pearson Product Moment Correlation Coefficient $(r)$ was computed to 
examine interjudge reliability between the graduate students and investigator. Interjudge reliability among the judges and the investigator ranged from .93 to .99 .

\section{DATA MEASUREMENT AND ANALYSIS}

Each subject's responses were transcribed and tape recorded on location. The APP-r manual guidelines for transcribing were followed. The CAPP was then used to score each child's responses. Symbols representing each child's response were typed into the computer. A one-page printout of the percentage of occurrence scores for ten phonological process deviations, a phonological deviancy score, and a goal statement was provided by the computer analysis program for each subject (Appendix D). The fifty target words of each subject were then analyzed using the CAPP to determine the percentage of occurrence of ten basic phonological process deviations including syllable reduction, prevocalic singleton omission, postvocalic singleton omission, consonant sequence reduction, strident deviation, velar deviation, liquid ( 1 ) and liquid ( $x$ ) deviations, nasal deviation, and glide deviation. In addition, a one-way analysis of variance was computed to determine if a statistical difference among age groups existed in both the number and type of phonological process deviations observed. The Introductory statistics Program for the Apple IIe Computer (Elzey, 1984) was used to analyze the data. An 
alpha level of .05 was used in determining statistical significance. 
CHAPTER IV

\section{RESULTS AND DISCUSSION}

The stated purpose of this study was to obtain normative data for the APP-r scores of children ranging from 2-10 to 5-2 years. The first question posed was: Do normally developing children exhibit phonological process deviations? The normal developing children ages 2-10 to 5-2 years in this study did exhibit phonological process deviations. Figures 2,3 , and 4 show the number of children from each age group that exhibited some of the ten basic phonological process deviations. Thirty-nine of the fifty subjects in this study exhibited at least one of the ten basic phonological process deviations. Eleven subjects did not exhibit any process deviations. The number of phonological process deviations produced by all children ranged from zero to eight, with a mean number of 3.24 and a standard deviation of 2.68 (Table IV).

All children in the 3-year-age group exhibited at least two basic phonological process deviations. The most frequently occurring phonological process deviations produced by this age group were consonant sequence reduction, strident deviation, liquid $/ 1 /$, and liquid $/ r /$. 
Eight of ten subjects exhibited these four process deviations. 


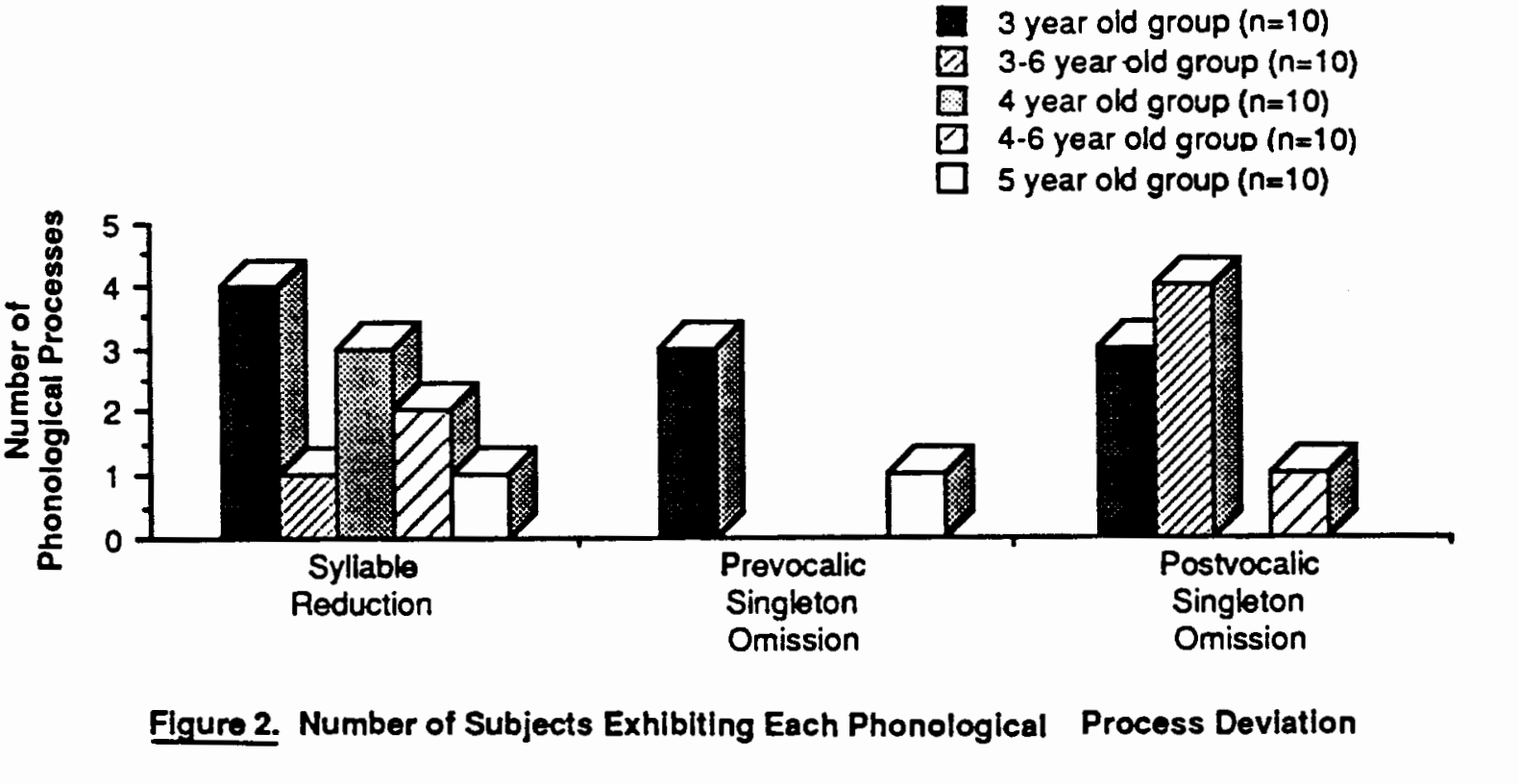

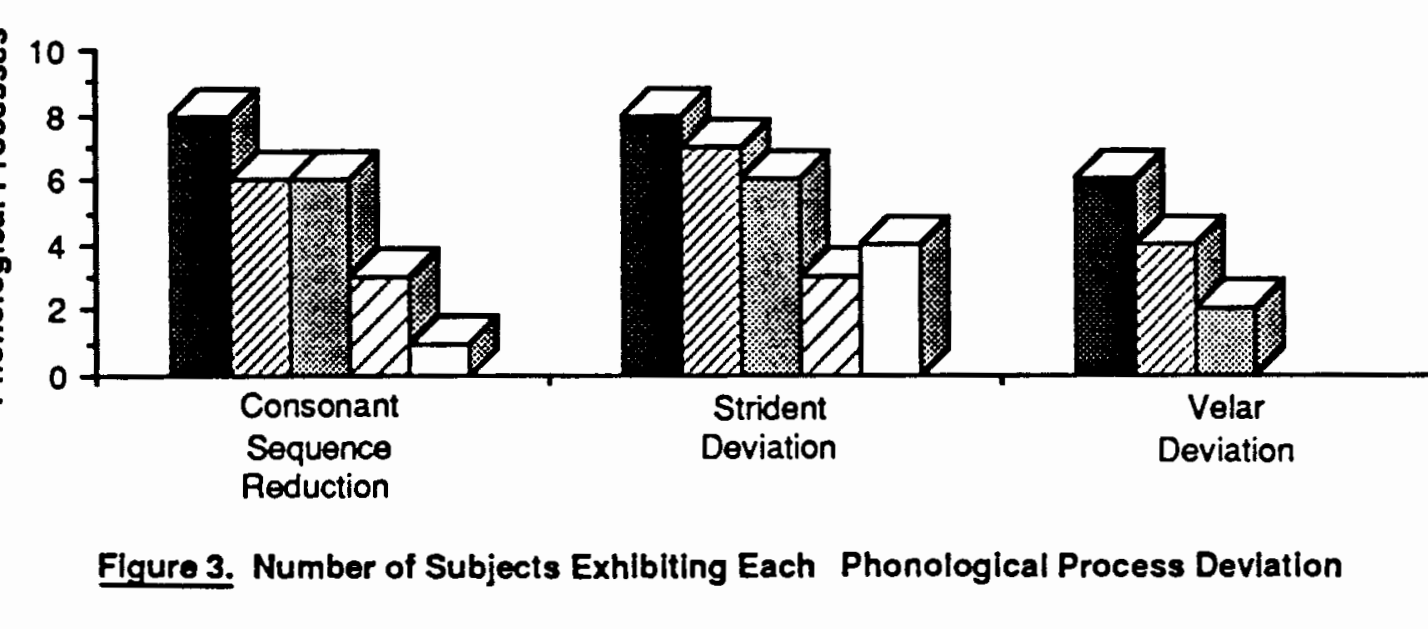

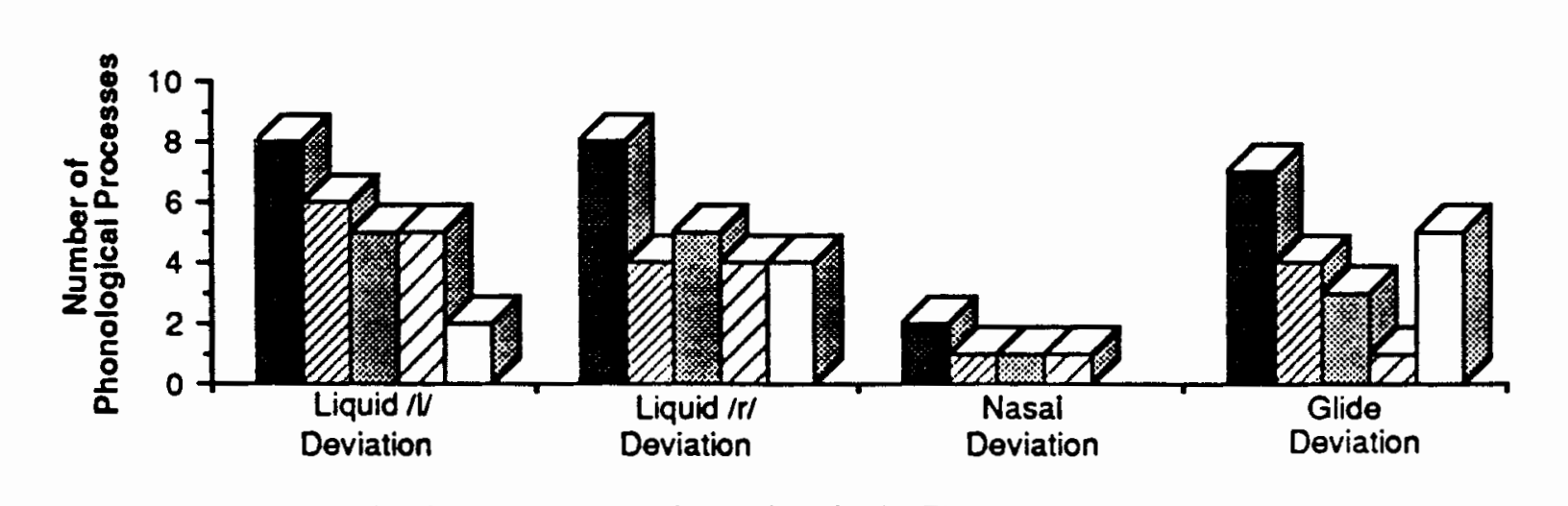


TABLE IV

$x$, SD, AND RANGE OF THE NUMBER OF PHONOLOGICAL PROCESS DEVIATIONS EXHIBITED BY ALL CHILDREN

\begin{tabular}{ccccc}
\hline Age & $\mathrm{n}$ & $\overline{\mathrm{x}}$ & $\mathrm{SD}$ & Range \\
\hline $2-10$ to $5-2$ & 50 & 3.24 & 2.68 & 0 to 8 \\
\hline
\end{tabular}

Seven subjects in the 3-6 year age group exhibited at least one basic phonological process. Strident deviation was the most frequently occurring process deviation in this age group. Seven of ten subjects exhibited strident deviation.

Nine subjects in the 4 -year age group produced at least one basic phonological process deviation. The most frequently produced process deviations were strident deviation and consonant sequence reduction. Six of ten subjects exhibited these process deviations.

Six subjects in the 4-6 year age group produced phonological process deviations. Liquid /1/ deviation was the most frequently occurring process with five of ten subjects exhibiting this deviation.

Seven subjects in the 5-year age group exhibited some phonological process deviations. Liquid $/ r /$ and strident deviations were the most frequently occurring process deviations. Only four of ten subjects exhibited these two process deviations. 
The second question posed was: What is the frequency of occurrence of each phonological process deviation by age group (Table V)? Figures 5, 6, and 7 show the average percentage of occurrence of each phonological process deviation among age groups. Liquid /1/ deviation resulted in the highest percentage of occurrence among the $3-0,3-6$, and 4-0 year-old age groups. Liquid $/ r /$ deviation resulted in the highest percentage of occurrence among the 4-6 and 50 year-old age groups. 
TABLE V

MEAN PERCENTAGE OF THE FREQUENCY OF OCCURRENCE OF EACH PROCESS DEVIATION BY AGE GROUP

PROCESS

DEVIATION

Syllable Reduction

Prevocalic

Singleton

Omission

Postrocalic

Singleton

Omission

Consonant

Sequence

Reduction

Strident

Deviation

Velar

Deviation

Liquid /1/

Deviation

Liquid $|r|$

Deviation

Nasal

Deviation

Glide

Deviation

$3-0 \quad 3-6^{A G E}$

3.7

1.1

2.1

1.6

.5

4-0

4-6

5-0

1.1

0

0

0

.2

1.2

1.5

0

0

0

20

12.6

4.8

1.6

.3

16.7

15.5

18.1

7.5

4.5

12.3

3.7

1.4

0

0

44.6

27.3

24.6

21.8

9.1

35.7

11.9

21

37.5

18.1

2.7

.5

.5

.5

0 


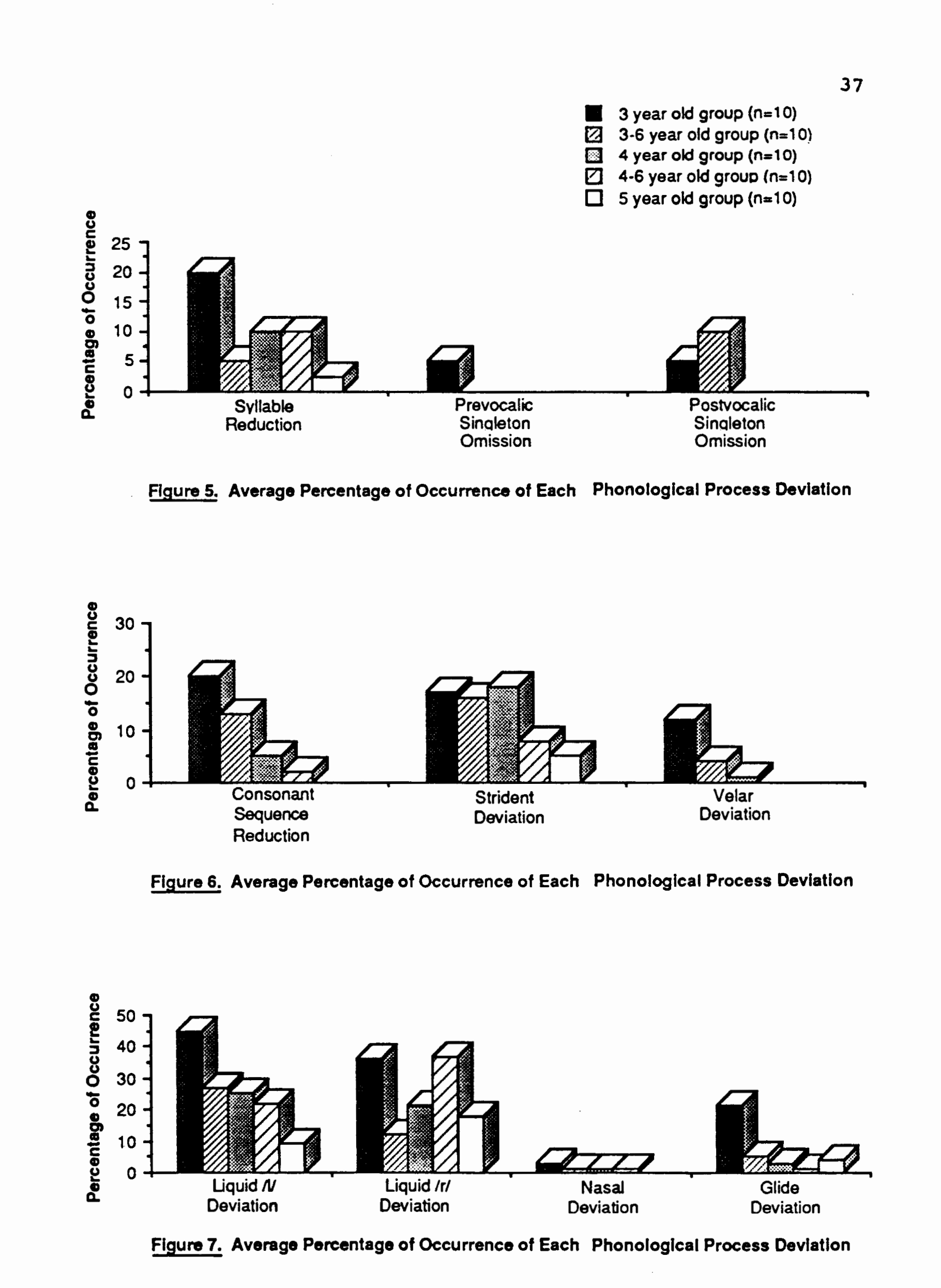


Prevocalic singleton omission, postrocalic singleton omission, and nasal deviation were rarely produced among all age groups. The average percentage of occurrence of phonological process deviation produced by all children ranged from 0 to 35 with a mean of 8.46 and a standard deviation of 8.69 (Table VI).

TABLE VI

$\bar{x}$, SD, AND RANGE OF THE AVERAGE PERCENTAGE OF POSSIBLE PHONOLOGICAL PROCESS DEVIATIONS

PRODUCED BY ALL CHILDREN

\begin{tabular}{ccccc}
\hline Age & $\mathrm{n}$ & $\overline{\mathrm{x}}$ & SD & Range \\
\hline $2-10$ to $5-2$ & 50 & 8.46 & 8.69 & 0 to 35 \\
\hline
\end{tabular}

The third question posed was: Does the number of phonological process deviations decrease as age increases? The mean number of phonological process deviations for the $3-0,3-6,4-0,4-6$, and 5-0 year-old age groups were $5.7,3.6,3.0,2.0$, and 1.7 , respectively (Table VII). 
TABLE VII

$x$, SD, AND RANGE OF THE NUMBER OF PHONOLOGICAL PROCESS DEVIATIONS EXHIBITED BY

EACH AGE GROUP

\begin{tabular}{lllll}
\hline Age Group & $\mathrm{n}$ & $\overline{\mathrm{x}}$ & $\mathrm{SD}$ & Range \\
\hline $2-10$ to $3-2$ & 10 & 5.7 & 2.45 & 0 to 8 \\
$3-4$ to $3-8$ & 10 & 3.6 & 2.37 & 0 to 8 \\
$3-10$ to $4-2$ & 10 & 3.0 & 2.36 & 0 to 6 \\
$4-4$ to $4-8$ & 10 & 2.0 & 1.70 & 0 to 6 \\
$4-10$ to $5-2$ & 10 & 1.7 & 1.70 & 0 to 4 \\
\hline
\end{tabular}

A one-way analysis of variance comparing the number of phonological process deviations for each age group yielded an f-ratio of 4.502, which is significant at the .05 level (Table VIII). This indicates that as age increases, the number of phonological processes produced decreases.

The fourth question posed was: Does the average total frequency of occurrence of phonological process deviations decrease as age increases? The mean percentage of phonological process deviations for the $3-0,3-6,4-0,4-6$, and 5-0 year-old age groups were $15.8,8.0,7.6,7.3$, and 3.6, respectively (Table IX). A one-way analysis of variance comparing the average percentage of possible phonological process deviations for each age group yielded an f-ratio of 3.088 , which is significant at the .05 level (Table $\mathrm{X}$ ). This indicates that as age increases, the percentage of phonological process deviations also decreases. 


\section{TABLE VIII}

ONE-WAY ANALYSIS OF VARIANCE COMPARING

THE NUMBER OF PHONOLOGICAL PROCESSES

PRODUCED FOR AGE GROUPS

\begin{tabular}{lccrrr}
\hline Source & SS & MS & df & $f$ & p \\
\hline Between Groups & 100.920 & 25.230 & 4 & 4.502 & .01 * \\
Within Groups & 252.200 & 5.604 & 45 & & \\
& & & & & \\
\hline *Significant at p & .05. & & & &
\end{tabular}

TABLE IX

$x$, SD, AND RANGE OF THE AVERAGE PERCENTAGE

OF POSSIBLE PHONOLOGICAL PROCESS

DEVIATIONS FOR EACH AGE GROUP

\begin{tabular}{llrrl}
\hline Age Group & $\mathrm{n}$ & $\overline{\mathrm{x}}$ & $\mathrm{SD}$ & Range \\
\hline $2-10$ to $3-2$ & 10 & 15.8 & 11.60 & 1 to 35 \\
$3-4$ to $3-8$ & 10 & 8.0 & 7.80 & 0 to 25 \\
$3-10$ to $4-2$ & 10 & 7.6 & 5.46 & 0 to 15 \\
$4-4$ to $4-8$ & 10 & 7.3 & 7.79 & 0 to 20 \\
$4-10$ to $5-2$ & 10 & 3.6 & 6.08 & 0 to 19
\end{tabular}


TABLE X

ONE-WAY ANALYSIS OF VARIANCE COMPARING

THE AVERAGE PERCENTAGE OF POSSIBLE

PHONOLOGICAL PROCESS DEVIATIONS FOR AGE GROUPS

\begin{tabular}{|c|c|c|c|c|c|}
\hline Source & SS & MS & $\mathrm{df}$ & 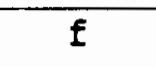 & $p$ \\
\hline $\begin{array}{l}\text { Between Groups } \\
\text { Within Groups }\end{array}$ & $\begin{array}{r}797.920 \\
2906.500\end{array}$ & $\begin{array}{r}199.480 \\
64.589\end{array}$ & $\begin{array}{r}4 \\
45\end{array}$ & 3.088 & $.025 \star$ \\
\hline
\end{tabular}

Normally developing children in this study exhibited phonological process deviations. Thirty-nine of fifty children ranging from 2 to 5-2 years exhibited phonological process deviations. The process deviations of consonant sequence reduction, strident deviation, and liquid /1/ deviation most frequently occurred in the $3,3-6$, and 4-year old children. Liquid $/ r /$ deviation was prominent in the $4-6$ and 5-year age groups. Nasal deviations and prevocalic singleton omissions were rarely produced across all age groups.

Liquid $/ 1 /$ and $/ r /$ deviations (includes gliding) and consonant sequence reduction (or cluster reduction) were analyzed in this study. These process deviations persisted beyond the age of three, which duplicates with the results of Stoel-Gammon and Dunn (1985) as shown in Table III. 
Postrocalic singleton omission (or final consonant deletion) was also analyzed in this study. The results of this study did not agree with stoel-Gammon and Dunn (1985). In this study postvocalic singleton omission was exhibited among the 3, 3-6, and 4-6 year age groups. Stoel-Gammon and Dunn (1985) show that this process disappears by age 3; children in this study produced this process deviation less than four percent in these age groups.

The results of this study agree with the developmental sequence listed by Hodson and Paden (1983), Kahn and Lewis (1985), and Weiner (1979). For example, deletion of final consonants (postvocalic singleton omission) and syllable reduction were rarely exhibited by subjects in this study. Hodson, Rahn and Lewis, and Weiner consider these process deviations early developing. The subjects in this study are not early developing. Subjects younger than 3 years would be expected to exhibit these process deviations. Strident deviations and liquid deviations were common among all age groups in this study. Hodson, Kahn and Lewis, and Weiner consider these process deviations later developing.

The frequency of occurrence of each phonological process deviation varied across age groups. Liquid /1/ deviation resulted in the highest percentage of occurrence among the $3,3-6$, and 4-year age groups. Liquid $/ x /$ deviation resulted in the highest percentage of occurrence among the 4-6 and 5-year age groups. Syllable reduction, 
prevocalic singleton omission, postrocalic singleton omission, and nasal deviation occurred only 5 percent or less within all age groups. The percentage of occurrence of liquid / $r /$ and liquid / $/ /$ minimumally decreased and persisted throughout all age groups.

As previously stated, Grunwell (1983) has listed a chronology of most commonly occurring phonological process deviations in children's speech development and their approximate age of mastery (Figure 1). Comparing this list with the results of this study reveals similarities in speech development. according to Grunwell, final consonant deletion disappears by 3-3 to 3-6 years of age. The results of this study agreed with Grunwell's findings. Cluster reduction disappears approximately by age 4-0 as stated by Grunwell. In this study, consonant sequence or cluster reduction was still present at 4-6; however, the percentage of occurrence among children in this age group was less than 5 percent. Grunwell also stated that gliding of liquids may persist until 4-0 to 5-0 years. The results of this study are in agreement with Grunwell. Liquid /1/ and liquid /r/ deviations persisted throughout all age groups.

The number of phonological process deviations decreased as age increased in this study. The results reveal a statistically significant difference when the number of process deviations produced at each age group is compared (Table VIII). A significant decrease in the number 
of phonological process deviations exhibited occurred at the 4-6 year level. For example, consonant sequence reduction and strident deviation occurred in eight subjects among the 3-year-old group and in only three subjects in the 4-6 yearold group. Velar deviation occurred in six subjects in the 3-year-old group and in no subjects in the 4-6 year-old group. Glide deviation occurred in seven subjects in the 3year old group and in only one subject in the 4-6 year-old group.

The average total frequency of occurrence of phonological process deviations also decreased as age increased in this study. This study's results reveal a significant difference when the average percentage of occurrence of all phonological process deviations is compared across age groups. The 5-year-old group produced less than 10 percent of all possible process deviations except for liquid $/ r /$ (Figures 5,6 , and 7 ). There was a dramatic decrease in the mean percentage of occurrence of phonological process deviations between $3-0$ and 5-0 years (Table VIII). A significant decrease between 4-6 and 5-0 years also resulted.

The most frequently occurring phonological process deviation across all age groups was liquid (1) and the least frequently occurring process was prevocalic singleton omission (Table XI). 
TABLE XI

PHONOLOGICAL PROCESS DEVIATIONS IN ORDER

OF FREQUENCY OF OCCURRENCE

Liquid /1/

Liquid / $/ \mathrm{r} /$

Strident Deviation

Consonant Sequence Reduction

Glide Deviation

Velar Deviation

Syllable Reduction

Nasal Deviation

Postvocalic Singleton Omission

Prevocalic Singleton Omission
25.48

24.64

12.46

7.92

6.80

3.48

1.80

.84

.60

.26

In summary, the mean numbers of phonological process deviations exhibited across age groups indicate a significant difference. As age increased the number of process deviations decreased. In addition, the percentage of occurrence of possible phonological process deviations exhibited across age groups differed significantly. As age increased the percentage of occurrence decreased. Although the number of subjects in this study is limited, the results of this study indicate that normative data can be obtained. 


\section{CHAPTER V}

\section{SUMMARY AND IMPLICATIONS}

Various methods of speech diagnosis have been developed arising from a need for speech-language pathologists to analyze articulation errors. Current attention has focused on phonological process analysis. This approach analyzes how a child simplifies an adult target form of a word.

Much of the research concerning phonological processes has focused on disordered articulation and various methods of analysis. Little research has been conducted on normal development. As a result, most phonological process tests are without norms. The Assessment of Phonological Processes - Revised (APP-r) developed by Hodson (1986) is one test of phonological process analysis and is without norms. The purpose of this study was to obtain normative data for children ranging from 3 to 5 years of age on their use of phonological process deviations as measured by the APP-r. The questions this study sought to answer were: Do normally developing children exhibit phonological process deviations: what is the frequency of occurrence of each phonological process deviation by age group; and does the number of phonological process deviations and the average total 
frequency of occurrence of phonological process deviations decrease as age increases?

Fifty subjects, ages 2-10 to 5-2 years participated in this study. Subjects were from preschools in the Portland metropolitan area.

The mean numbers of phonological process deviations exhibited by the $3,3-6,4,4-6$, and 5-year age groups were $5.7,3.6,3.0,2.0$, and 1.7 , respectively. The mean percentage of all phonological process deviations exhibited for each age group were $15.8,8.0,7.6,7.3$, and 3.6, respectively. A one-way analysis of variance revealed a statistically significant difference at the .05 level when the number of ten basic process deviations exhibited was compared across age groups. In addition, a one-way analysis of variance comparing the average percentage of all phonological process deviations exhibited across age groups was statistically significant at the .05 level. As age increased, the use of phonological processes decreased.

The results of this study reveal that as age increases, the number of process deviations decrease. In addition, the average percentage of process deviations decrease as age increases. Liquid $/ 1 /$, and $l i q u i d / r /$, and strident deviations were most commonly exhibited across all age groups and prevocalic singleton omission, postvocalic singleton omission, and nasal deviation were rarely exhibited across all age groups. Although the number of 
subjects that participated in this study is limited, information gathered may be helpful in assessing disordered articulation with knowledge of expected performance.

\section{IMPLICATIONS}

\section{$\underline{\text { Research }}$}

Further research regarding phonological process development is warranted. A replication of this study could be conducted using a larger sample size, which would result in a more representative sample. In addition, other phonological process deviations beyond the ten basic phonological process deviations could be analyzed in this study.

Research using younger or older children could be conducted in order to obtain an overall description across ages. Other phonological process analyses could be utilized to assess a subject's normal speech development. For example, some phonological analyses utilize a spontaneous speech sample, as opposed to the single naming of words used here. Research could specify the differences that may exist between the two methods.

Particular emphasis on normal speech development at one-age level could also be investigated. 


\section{Clinical}

Results of the current study may help to provide a framework for phonological process development. Normative data can be helpful in assessing whether a child's speech may be delayed or disordered. Grunwell (1983) states that early process deviations are usually exhibited in child speech disorders and that many of the patterns are similar to those observed in normal speech development. This suggests that a child who continues to produce developmental phonological process deviations could be identified using a framework on normative phonological process development.

Results from this study may serve in planning remediation with articulation disordered children. Most studies have been concerned with reporting the differences among normal and articulation disordered or normal and language disordered children. The results of this study are focused solely on normal developing children and add to the existing literature in creating a basic foundation regarding normal phonological speech development. 
REFERENCES

CHOMSRY, N., and HALLE, M. (1968). The sound pattern of English. New York, NY: Harper and Row.

COMPTON, A.J. and HUTTON, J.S. (1978). Compton-Hutton phonological assessment. San Francisco, CA: Carosel House.

EDWARDS, M.L. (1973). The acquisition of liquids, working papers in linguistics. In Edwards, M.L. and Shriberg, L.D., Phonology applications in communicative disorders. San Diego, CA: College-Hill Press.

ELBERT, M. and GIERUT, J.A. (1986). Handbook of clinical phonology approaches to assessment and treatment. San Diego, CA: College-Hill Press.

ELZEY, F.F. (1985). Introductory statistics: a microcomputer approach. Monterey, CA: Brooks/Cole Publishing.

GOLDMAN, R., and FRISTOE, M. (1969). Goldman-Fristoe test of articulation. Circle Pines, MN: American Guidance Press.

GRUNWELL, P. (1983). Clinical phonology. Rockville, MD: Aspen systems Publication.

HAELSIG, P. and MADISON, C.L. (1986). A study of phonological processes exhibited by 3-, 4-, and 5-year old children. Language, Speech, and Hearing services Schools, 17, 107-114.

HODSON, B.W. (1986). The assessment of phonological processes - revised. Danville, IL: Interstate Printers and Publishers.

HODSON, B.W. (1985). Computer analysis of phonological processes. Stonington, IL: Phonocomp.

HODSON, B.W. and PADEN, E.P. (1981). Phonological processes which characterize unintelligible and intelligible speech in early childhood. Journal of Speech and Hearing Disorders, 46, 369-373. 
HODSON, B.W. and PADEN, E.P. (1983). Targeting intelligible speech. San Diego, CA: College-Hill Press.

INGRAM, D. (1974). Phonological rules in young children. Journal of Child Language, 1, 49-64.

INGRAM, D. (1981). Procedures for the analysis of children's language. Baltimore, MD: University Park Press.

KAHN, L.M. (1985). Basis of phonological analysis: a programmed learning text. San Diego, CA: CollegeHill Press.

KAHN, L.M. and LEWIS, N. (1985). Kahn-Lewis phonological analysis. Circle Pines, MN: American Guidance Service.

LEONARD, L.B., MILLER, J.A. and BROWN, H. (1980). Consonant and syllable harmony in the speech of language disordered children. Journal of Speech and Hearing Disorders, 45, 336-345.

OLLER, D.K. (1973). Regularities in abnormal child phonology. Journal of Speech and Hearing Disorders, $38,36-47$.

PREISSER, D. (1983). Unpublished doctoral dissertation, San Diego State University, CA.

SCHWARTS, R.G., LEONARD, L.B., FOLGER, K.M., and WILCOX, M.J. (1980). Early phonological behavior in normalspeaking and language-disordered children: Evidence for a synergistic view of linguistic disorders. Journal of Speech and Hearing Disorders, 46, 197-204.

SHRIBERG, L.D. and KWIATROWSRI, J. (1980). Natural process analysis (NPA): a procedure for phonological analysis of continuous speech samples. New York, NY: John wiley and Sons.

SMITH, N.V. (1973). The acquisition of phonology: a case study. In Edwards, M.L. and Shriberg, L.D., Phonology applications in communicative disorders. San Diego, CA: College-Hill Press.

STAMPE, D. (1969a). The acquisition of phonetic representation, Papers from the fifth regional meeting of the Chicago Linguistic Society. In Elbert, M., and 
Gierut, J.A., Handbook of clinical phonology approaches to assessment and treatment. San Diego, CA: College-Hill Press.

STAMPE, D. (1969b). The acquisition of phonetic representation, Papers from the fifth regional meeting of the Chicago Linguistic Society. In Kahn, L.M., Basis of phonological analysis: a programmed learning text. San Diego, CA: College-Hill Press.

STAMPE, D. (1969c). The acquisition of phonetic representation, Papers from the fifth regional meeting of the Chicago Linguistic Society, (pp443-454). In Edwards, M. and Shriberg, L., Phonology applications in communicative disorders. San Diego, CA: CollegeHill Press.

STAMPE, D. (1972). How I spent my summer vacation. In Edwards, M.L., and Shriberg, L., Phonology

applications in communicative disorders. San Diego, CA: College-Hill Press.

STOEL-GAMMON, C. and DUNN, C. (1985). Normal and disordered phonology in children. Baltimore, MD: University Park Press.

WEINER, F.F. (1979). Phonological process analysis. Baltimore, MD: University Park Press.

WEISS, C.E., GORDON, M.E., and LILLYWHITE, H.S. (1987). Clinical management of articulatory and phonologic disorders. Los Angeles, CA: Williams and Wilkins. 
APPENDIX A

\section{PHONOLOGICAL PROCESS DEFINITIONS}

Affrication: occurs when an affricate replaces a fricative (e.g.,/tsan/ for "sun").

Articulatory Shifts: processes in which there are "minimal shifts" in place of articulation (e.g., frontal lisp).

Backing: occurs when a target sound is replaced with another sound whose place of articulation is posterior to it (e.g., /go/ for "toe").

Coalescence: the use of one consonant which shares the features of two consonants of a cluster (e.g.. / ten/ for "plane").

Deaffrication: process of replacing an affricate with a nonaffricate (e.g.. / $\zeta C$ / for "chair").

Depalatization: occurs when a palatal consonant is replaced by a nonpalatal (e.g., /mæs/ for "mash").

Diminuization: process of adding an / $i /$ or consonant plus /i/ to a word (e.g., /dagi/ for "dog").

Doubling: process of repeating a word le.g., /baba/ for "ball").

Epenthesis: refers to the addition of a vowel to a word (e.g., /bolak/ for "black").

Fronting: occurs when a target phoneme is replaced with another sound whose place of articulation is anterior to it (e.g., /tau/ for "cow").

Gliding: use of a glide $(/ w, j /)$ for another consonant (e.g., /wen/ for "rain").

Glottal Replacement: process of substituting a glottal stop for a consonant (e.g., /bz / for "bath"). 
Neutralization: occurs when several different phonemes are replaced by one sound (e.g., /jun/ for "sun" and /ju/ for "juice").

Metathesis/Migration: process of reordering or reversing a word (e.g., / - lant/ for "elephant").

Prevocalic Voicing: refers to voicing an unvoiced consonant when it precedes a vowel (e.g., /big/ for "pig").

Postrocalic Voicing: changing a voiced obstruent at the end of a word to a voiceless obstruent (e.g., /liv/ for "leaf").

Stopping: occurs when ficatives, afficates, liquids, and glides are replaced by stops (e.g., /kit/ for "kiss").

Syllable Harmony: refers to the repetition of all or part of a syllable (e.g., /nudu/ for "noodle").

Vocalization: process in which a vowel is substituted for a syllabic consonant (e.g., /kau/ for "car").

Weak Syllable Deletion: occurs when the unstressed syllable of a multisyllabic word is omitted (e.g., /teto/ for "potato"). 


\section{APPENDIX B}

COILLEE UF

RAL ARTS ANO SCIENCES

DEPARTMENT ()F

ECH COMMUNICATION

SPEECH AND

HEARING SCIENCES

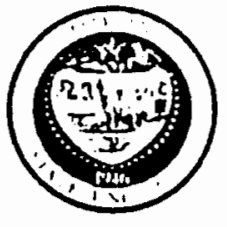

POKILANI)

SINIF

UNIVFRSIIY

12. 1). IIX IX

PURIIANI). CIRI (IIN

ग: 2117

5111/221.3533

Dear Parent or Guardian,

I am a graduate student at Portland state University in the Department of Speech Communication. Under the direction of Mary E. Gordon. Associate Professor, I am conducting a study on normal speech development in children ages three years to five years. This information will help speech-language clinicians identify and provide services to preschoolers and schoolaged children who need speech intervention.

If your child participates in this study, he/she will be given a brief hearing screening and a test in which he/she will name toys and objects. Your child will be naming toys and objects because we want to observe how children pronounce words at this age. The testing session will last approximately 20 minutcs. During the naming activity, your child will be tape recorded. Your child's name will not be used in reporting the results and audio tapes will be used only for a research study. You may withdraw your child at any time without consequence.

In addition to the testing session for your child, the study involves your completing a brief questionnaire regarding your child's speech and language development and medical history. Please complete this attached form and indicate your approval for your child to participate in this study and return it to the school as soon as possible.

Please call me if you have any questions (home - 653-9829 or school - 229-3533). Thanks for your cooperation.

If you have any problems that are the result of your participation in this study, please contact Robert Tinnin, Office of Graduate Studies and Research, 105 Neuberger Hall, Portland State University at 229-3423. 
PERMISSION FORM

CHILD'S NAME:

BIRTHDATE :

AGE :

1. Has your child had a history of speech and/or language problems? yes no

2. Has your child had a history of ear infections? yes__ no

3. Has your child ever been diagnosed as demonstrating any of the following:

neurological impairment yes__ no

mental retardation yes__ no

developmental delay yes__ no ___

I hereby give my permission for my child, to participate in this study. My child may participate in a hearing screening and a speech testing session at the Helen Gordon Child Development Center.

I will complete the questionnaire and I understand that I may withdraw my permission at any time during this study without consequence. 
57

APPENDIX C

THE ASSESSMENT OF PHONOLOGICAL PROCESSES -Revised Barbara VYllilams Godson

Name Birthrate Date Examiner

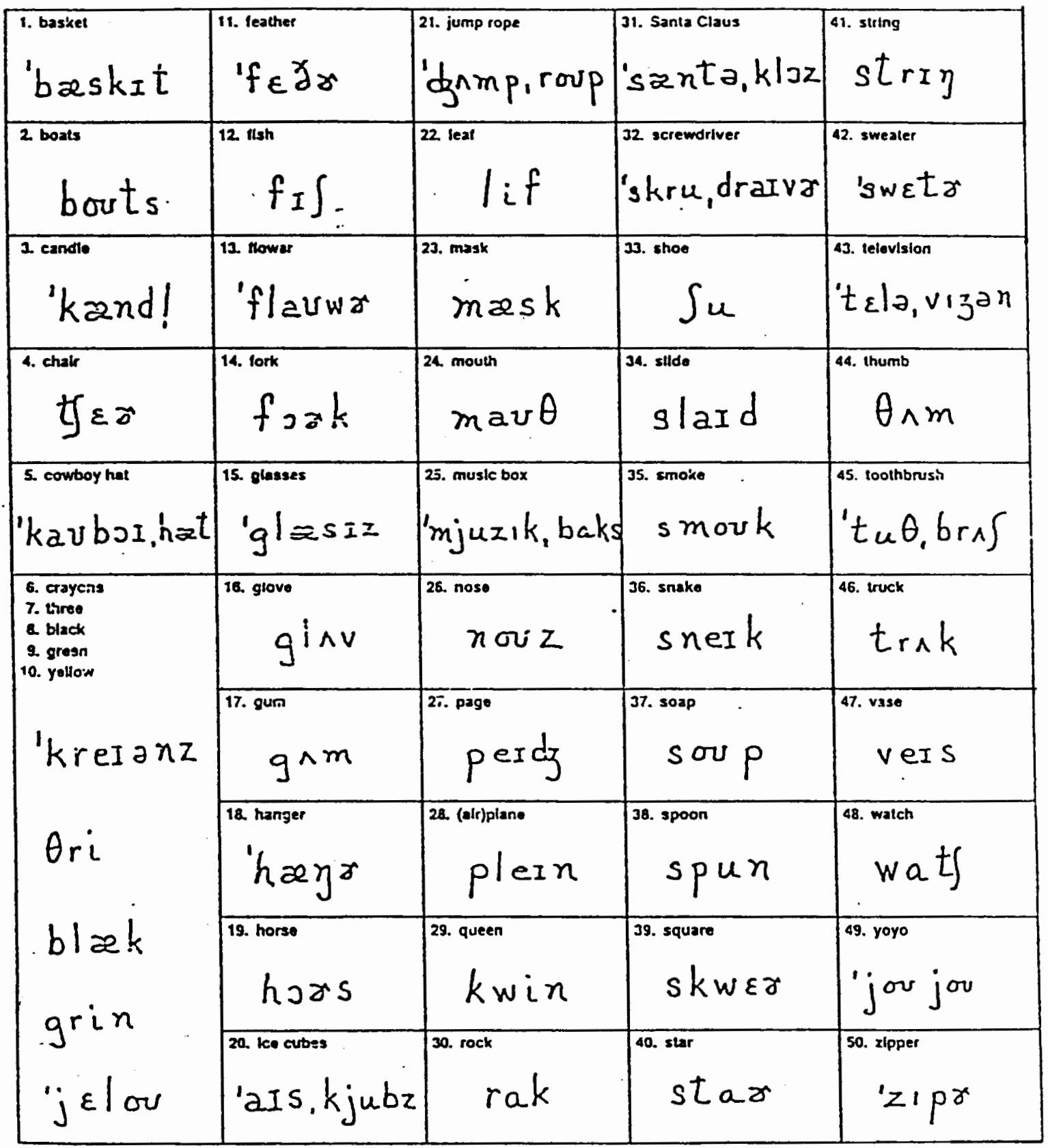




\section{APPENDIX D}

Name of Client:

Date of Birth: 4-3-83

Date of Phonological: 3-1-87

Age in Years: 3

Examiner's Name: LORI GRIFFITH

Diagnostic Information:

\section{Phonological Analysis Summary}

Pattern Deviations

Syllable Reduction

Prevocalic Singletons

Postvocalic Singletons

Consonant sequences

Stridents

Velars

Liquid (1)

Liquid (r)

Nasals

Glides
Percentage of Occurrence

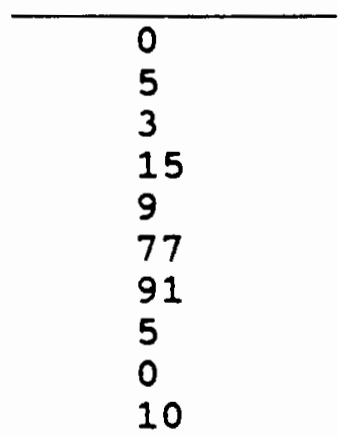

Average of Phonological Processes: 22

Phonological Deviancy Score: 22

Severity Interval: Moderate

GOAL: To increase intelligibility by facilitating emergence of the following phonological patterns:

Velars

Liquid

COMPUTER ANALYSIS Of PHONOLOGICAL PROCESSES

Barbara Williams Hodson

Copyright 1985; PhonoComp 